\title{
About Six in Ten Survivors of the November 2020 Maikadra Massacre Suffer from Posttraumatic Stress Disorder, Northwest Ethiopia
}

\author{
Dawed Ali', Telake Azale², Melese Wondie', Jinenus Tadesse' \\ 'University of Gondar, College of Medicine and Health Sciences, Department of Psychiatry, Gondar, Ethiopia; ${ }^{2}$ University of Gondar, College of \\ Medicine and Health Sciences, Department Health Education and Behavioral Sciences, Gondar, Ethiopia \\ Correspondence: Telake Azale, University of Gondar, College of Medicine and Health Sciences, Department of Health Education and Behavioral \\ Sciences, PO Box 196, Gondar, Ethiopia, Tel +25I 91877195I, Email atelake07@gmail.com
}

\begin{abstract}
Background: Post-traumatic stress disorder (PTSD) is characterized by recurrent, involuntary, and intrusive distressing memories of a traumatic event and dissociative reactions. Little is known about post-traumatic stress disorder in low and middle income countries such as Ethiopia where armed conflict, human rights violations, and ethnic-based violence are becoming everyday occurrences.

Objective: This study aimed to assess the prevalence of post-traumatic stress disorder and associated factors among residents of Maikadra, North West Ethiopia.

Methods: A community-based cross-sectional study was employed in April 2021. A multi-stage cluster sampling technique was employed to select the study participants. A post-traumatic stress disorder checklist (PCL-5) was used to assess post-traumatic stress disorder through a face-to-face interview. Bivariate and multi-variable binary logistic regression analyses were carried out to examine the association between posttraumatic stress disorder and several demographic and psychosocial variables. Statistical significance was declared at a $P$-value $<0.05$.

Results: A total of 610 participants were interviewed with a response rate of $98.8 \%$. The prevalence of PTSD in this study was $59.8 \%$ with a 95\% CI of 55.7-63.9. Female sex $(\mathrm{AOR}=1.93,95 \% \mathrm{CI}=1.64-3.24)$, having a close family member killed or seriously injured $(\mathrm{AOR}=1.96,95 \% \mathrm{CI}=1.1-3.48)$, having moderate $(\mathrm{AOR}=3.35,95 \% \mathrm{CI}=1.98-5.68)$ and high perceived threat to life $(\mathrm{AOR}=3.66,95 \%$ $\mathrm{CI}=1.85-6.95)$, having depression $(\mathrm{AOR}=1.67,95 \% \mathrm{CI}=1.13-2.47)$ and anxiety disorder $(\mathrm{AOR}=1.85,95 \% \mathrm{CI}=1.21-2.83)$, and being directly exposed to the event $(\mathrm{AOR}=3.27,95 \% \mathrm{CI}=1.09-9.83)$ were significantly associated with post-traumatic stress disorder.

Conclusion: The majority of the residents of Maikadra town where the November 2020 massacre took place experienced posttraumatic stress disorder. Female sex, having a family member or a friend murdered or seriously injured, having depression and anxiety disorders and being directly exposed to the trauma were found to be significant predictors of post-traumatic stress disorder. People who have been exposed to such an intense traumatic event need psychosocial support to help them recover from the horrible experiences.
\end{abstract} Keywords: PTSD, prevalence, Maikadra, survivors, Ethiopia

\section{Introduction}

The number of people being forcibly displaced by conflicts, political instability, and economic crises has been growing in different parts of the world. A wide range of unpleasant and stressful experiences that people encounter before and after leaving their homes contribute to the development of mental illnesses. ${ }^{1}$ Only 20 sub-Saharan African countries contribute to more than half of the global instability and conflict. $^{2}$

Post-traumatic stress disorder is the most common mental disorder following exposure to a traumatic event. ${ }^{3}$ Posttraumatic stress disorder is characterized by re-experiencing the traumatic event, avoidance, and hyper-arousal symptoms that can negatively impact mood and physiologic health.,

According to the result of a meta-analysis, about 242 million adult war survivors residing in post-war regions are estimated to suffer from PTSD and about 238 million adult survivors of war suffer from major depressive disorder. ${ }^{6}$ The $^{-}$ 
contributions of post-traumatic stress disorder (PTSD) to the global burden of disease is estimated to be almost $4 \%$ of the world's population. ${ }^{7}$ According to population-based studies, the prevalence of PTSD is estimated to be between 2 and $15 \%,{ }^{8}$ with a prevalence of $58 \%$ in high-risk groups. ${ }^{9}$ In comparison to the developed world, there are few studies on the prevalence of post-traumatic stress disorder (PTSD) in low-income countries. ${ }^{10}$ Available evidence indicates that war and political violence are associated with high rates of PTSD. ${ }^{11}$ The major contributing factors for the development of PTSD have been divided into four categories. These are preexisting factors such as mental illness and drug use in the family, the traumatic event itself, level of exposure, and post-trauma factors such as social support. ${ }^{12}$

Individuals suffering from PTSD have the potential to influence public and mental health outcomes in several ways next to large number of immediate direct casualties in combatants and civilians. ${ }^{7,10,13}$ It is also associated with substantial psychiatric comorbidity, ${ }^{14}$ increased risk of suicide, and considerable economic burden. ${ }^{15,16}$ In low- and middle-income nations, it is estimated that $77 \%$ of people with PTSD do not receive treatment. ${ }^{7}$

In African countries, particularly in sub-Saharan Africa (SSA), the majority of people with PTSD don't receive treatment and are at an increased risk of developing chronic symptoms. ${ }^{2}$ Conflict has long-term mental health consequences after the events are over, and therefore mental health interventions are as urgent for post-conflict populations as physical health and other emergency interventions. ${ }^{17}$ PTSD could result in long-term adverse consequences if left untreated, mainly it leads to social and functional impairments in survivors of conflict. ${ }^{18}$

According to meta-analysis conducted on a global population of adult war survivors that reviewed all countries that suffered at least one war within their own territory between 1989 and 2015 found that $23.81 \%$ of adult war survivors met diagnostic criteria for PTSD. ${ }^{6}$ A community- based cross-sectional study done in Nepal reported the prevalence of posttraumatic disorder to be $9.6 \% .^{19}$

Meta-analysis conducted in Iranian population following disasters and wars showed that the pooled prevalence of PTSD was $47 \%{ }^{20}$ A community based cross-sectional study done in Palestinie on those who live in West Bank, Gaza, and East Jerusalem, reported $23.8 \%, 23.9 \%$, and $17.9 \%$ prevalence estimates, respectively. ${ }^{21}$ In a similar study done in Palestine following intifada-related injuries, the estimated prevalence of post-traumatic stress disorder was $76.5 \%{ }^{22}$

According to two studies done in Negoma community in Rwanda on heavily affected population by genocide at different periods, the prevalence of PTSD was $24.8 \%{ }^{24}$ and $21.6 \%,{ }^{25}$ respectively. Additionally, two regional studies done on eight districts in Uganda reported the prevalence of PTSD was $54 \%{ }^{26}$ and $74.3 \%$, respectively. ${ }^{27}$

Another study conducted in Liberia after armed violence and conflict showed that the prevalence of PTSD assessed was $48.3 \%{ }^{28}$ Another study done in Niger Delta region, Nigeria, on a population heavily exposed to conflict, the prevalence of PTSD was $60 \% .{ }^{30}$ Similarly, in research done among survivors of terrorist attacks in North-East Nigeria, the prevalence of post-traumatic disorder was $65.72 \%{ }^{31}$

In a study conducted in Kenya in 2015 after Election violence, the prevalence of PTSD was $10.6 \% .^{32}$ Another hometo-home survey in Kenya among heads of households of ethnic clash survivors showed the prevalence of PTSD was $80.2 \%{ }^{33}$

Another community-based study conducted in South Sudan reported the prevalence of PTSD to be $28.1 \%{ }^{34}$

According to an institutional-based cross-sectional study done in southern Ethiopia the prevalence of probable PTSD was $15.4 \%$. Research conducted in Ethiopia on an internally displaced community reported the prevalence of PTSD to be 58.4\%. ${ }^{12}$ Another community-based cross-sectional study conducted in Ethiopia among Koshe landslide survivors showed that the prevalence of PTSD was $37.3 \%{ }^{35}$

There are several factors associated with the occurrence of post-traumatic stress disorder following exposure to traumatic events.

These factors include female sex ${ }^{36}$ unemployment, and low educational status. ${ }^{40-42}$ Moreover, younger age, being unmarried, lower socioeconomic status, and unemployment ${ }^{43}$ have been frequently reported as predictors of posttraumatic stress disorder. Studies done among internally displaced people and those exposed to landslides in Ethiopia identified that females were more likely to develop PTSD than males. ${ }^{12}$

Apart from the demographic characteristics of individuals, a history of mental illnesses is a predictor of posttraumatic stress disorder. ${ }^{42}$ Specifically, a history of depression was significantly associated with post-traumatic stress disorder. $^{12,38}$ 
Poor social support, medical conditions, and the use of psychoactive substances are among the strong predictors of post-traumatic stress disorder. ${ }^{18,38,44}$

Despite the burgeoning evidence of high prevalence of post-traumatic stress disorder in conflict-affected countries around the world, only a few studies with highly variable estimates have been published in Ethiopia where armed conflict, ethnic-based violence, and terrorist attacks are becoming very rampant.

This study is therefore aimed at determining the prevalence of post-traumatic stress disorder and its predictors among the population of Maikadra town where a serious massacre occurred that resulted in the death of more than 1,650 innocent civilians of the Amhara ethnic group.

\section{Methods and Materials}

A community-based cross-sectional study was conducted in April 2021 at Maikadra town, North West Ethiopia. The estimated total population was 27,840. About 4,500 individuals, mainly from Amhara region, had been there as seasonal migrant farm workers during the mass killings that took place in November 2020. This study was conducted among adult residents of the town. A total of 617 residents were randomly selected and recruited into the study. We used cluster sampling to select the lowest administrative units in the town called "kebeles". Two out of five "kebeles" were randomly selected. Each "kebele" has five sub-units called "ketena" which consist of 150 households. We selected five "ketenes" from the two randomly selected "kebeles". Then the data collectors interviewed each adult fulfilling the inclusion criteria in all of the five "ketenas".

\section{Measurement and Data Collection}

Post-traumatic stress disorder was measured by using a 20-item post-traumatic checklist (PCL-5) with scores ranging from $0-80$. A score of $\geq 33$ was considered positive for PTSD. ${ }^{45}$

Social support was measured by the Oslo-3 social support scale which ranges from 3-14. Those respondents who scored between 3 and 8 were considered to have poor social support, a score of 9-11 was considered to have moderate social support, and a score of $12-14$ was considered strong social support. ${ }^{46}$

Perceived life threat was measured using the perceived stress (PSS) scale which ranges from 0 to 40 . Those respondents who scored 0-13 on PSS were considered to have low perceived stress, a score between 14 and 26 was considered moderate perceived stress, and those who scored 27-40 were considered to have high perceived stress. ${ }^{47}$

Depression was measured by Patient Health Questionnaire (PHQ-9) with a score of 10 or more suggesting depression. ${ }^{50}$

Data were collected by two psychiatric professionals who visited the selected households and interviewed randomly selected adults using the Amharic version of the questionnaire.

Data were coded and entered into the computer using Epi data version 4.2 and then exported to Statistical Package for Social Science (SPSS) version 25 for analysis. Binary logistic regression was used to identify factors associated with the outcome variable.

\section{Results}

A total of 610 participants out of 617 were included in the study with a response rate of $98.8 \%$. The mean age $( \pm \mathrm{SD})$ of the respondents was $35( \pm 13.03)$ years, with the age range of $18-65$ years. Among the respondents, $348(57 \%)$ were males, $539(88.4 \%)$ were orthodox by religion and 371 (60.8\%) were married. Regarding educational status, $213(34.9 \%)$ of the participants were unable to read and write (Table 1).

Out of the respondents, $38(6.2 \%)$ had a family history of mental illness and seven (1.1\%) had been treated for mental illness. About a quarter, 153 (25.1\%) of the respondents, had chronic medical conditions of different types. Close to half of the study participants were screened positive for depression, $322(52.8 \%)$ and anxiety, 296 (48.5\%).

At the time of interview, 274 (44.9\%), 127 (20.8\%), and 121 (19.9\%) were using alcohol, Khat, and tobacco, respectively.

In this study, $382(62.6 \%)$ of the total participants said they had poor social support and more than half (52.6\%) had a moderate perceived life threat. 
Table I Socio-Demographic Characteristics of Study Participants of Mai Kadra, North West Ethiopia, $2021(n=610)$

\begin{tabular}{|c|c|c|c|}
\hline Variables & Categories & Frequency & Percent \\
\hline \multirow[t]{2}{*}{ Sex } & Male & 348 & 57.0 \\
\hline & Female & 262 & 43.0 \\
\hline \multirow[t]{3}{*}{ Religion } & Orthodox & 539 & 88.4 \\
\hline & Muslim & 66 & 10.8 \\
\hline & Other $^{\mathrm{a}}$ & 5 & 0.8 \\
\hline \multirow[t]{4}{*}{ Marital status } & Single & $|5|$ & 24.7 \\
\hline & Married & 362 & 59.3 \\
\hline & Divorced & 69 & 11.3 \\
\hline & Widowed & 28 & 4.6 \\
\hline \multirow[t]{5}{*}{ Educational level } & Unable to read and write & 213 & 34.9 \\
\hline & Primary school & 182 & 29.02 \\
\hline & Secondary school & 177 & 29.3 \\
\hline & Diploma & 33 & 5.4 \\
\hline & Degree and above & 5 & 0.82 \\
\hline \multirow[t]{7}{*}{ Occupational status } & Government employee & 31 & 5.1 \\
\hline & Student & 56 & 9.2 \\
\hline & Farmer & 144 & 23.6 \\
\hline & Housewife & 81 & 13.3 \\
\hline & Daily laborer & 66 & 10.8 \\
\hline & Merchant & 96 & 15.7 \\
\hline & Unemployed & 136 & 22.3 \\
\hline
\end{tabular}

Note: ${ }^{\mathrm{a} C}$ atholic, Protestant.

Concerning the level of exposure to the traumatic event, 439 (72\%) witnessed others being brutally killed and 151 $(25 \%)$ were themselves involved in the process but survived.

\section{Prevalence of Post-Traumatic Stress Disorder}

In the current study, the estimated prevalence of post-traumatic stress disorder was $59.8 \%(95 \% \mathrm{CI}=55.7-63.9)$ with an estimated prevalence of $46.6 \%$ and $71 \%$ among males and females, respectively.

\section{Factors Associated with PTSD}

Female sex, being single, being unemployed, having destruction of personal property, having chronic medical illness, a family history of mental illness, being screened positive for depression and anxiety, using alcohol, Khat, and tobacco, poor social support, moderate and high levels of perceived life threat, having a family member or a close friend injured/ killed, and direct exposure to the event were significantly associated with post-traumatic stress disorder at a $P$-value $\leq 0.2$. Then these variables were entered into the multivariable logistic regression model to control the confounding effects between the variables. 
The multi-variable analysis identified that female sex, having a family member or close friend seriously injured or killed, having depression and anxiety, being directly exposed to the traumatic event, and having moderate and high perceived life threat were significantly associated with PTSD at a $P$-value less than 0.05 .

Women were nearly twice aslikely to experience PTSD compared to men ( $\mathrm{AOR}=1.93,95 \% \mathrm{CI}=1.64-3.24)$. The odds of PTSD were 3-times more in those with high perceived threat to life (AOR=3.35, 95\% CI=1.98-5.68). Having depression ( $\mathrm{AOR}=1.67,95 \% \mathrm{CI}=1.13-2.47)$ and anxiety $(\mathrm{AOR}=1.85,95 \% \mathrm{CI}=1.21-2.83)$ were significantly associated with post-traumatic stress disorder. The odds of developing PTSD was 2-times higher among individuals whose family members or friends were seriously injured/killed ( $\mathrm{AOR}=1.96,95 \% \mathrm{CI}=1.10-3.48$ ). Participants who had been directly exposed to the traumatic event were 3.3-times more likely to have post-traumatic stress disorder ( $\mathrm{AOR}=3.27,95 \%$ CI=1.09-9.83) (Table 2).

Table 2 Bi-Variable and Multi-Variable Regression Analysis Showing Associations Between Independent Variables and Post-Traumatic Stress Disorder Among Residents of Mai Kadra, North West Ethiopia, 2021 ( $n=6 \mid 0)$

\begin{tabular}{|c|c|c|c|c|c|}
\hline & & \multicolumn{2}{|c|}{ PTSD } & \multirow[b]{2}{*}{ COR } & \multirow[b]{2}{*}{ AOR $(95 \% \mathrm{Cl})$} \\
\hline & & Yes & No & & \\
\hline \multirow[t]{2}{*}{ Sex } & Male & 179 & 169 & I & I \\
\hline & Female & 186 & 76 & $2.31(1.64-3.24)$ & $1.93(1.27-2.92)^{* *}$ \\
\hline \multirow[t]{4}{*}{ Marital status } & Single & 105 & 46 & $1.75(1.17-2.62)$ & $1.35(0.82-2.21)$ \\
\hline & Married & 205 & 157 & I & I \\
\hline & Divorced & 38 & 31 & $0.94(0.56-1.58)$ & $0.73(0.40-1.34)$ \\
\hline & Widowed & 17 & II & $1.18(0.54-2.60)$ & $1.06(0.42-2.70)$ \\
\hline \multirow[t]{7}{*}{ Occupational status } & Government employee & 14 & 17 & I & I \\
\hline & Student & 29 & 27 & $1.30(0.54-3.15)$ & $0.98(0.35-2.76)$ \\
\hline & Farmer & 78 & 66 & $1.43(0.66-3.13)$ & I. $12(0.45-2.76)$ \\
\hline & Housewife & 54 & 27 & $2.43(1.04-5.65)$ & $0.92(0.33-2.56)$ \\
\hline & Daily labor & 33 & 33 & $1.21(0.52-2.86)$ & $0.88(0.33-2.38)$ \\
\hline & Merchant & 63 & 33 & $2.32(1.02-5.28)$ & $1.51(0.58-3.95)$ \\
\hline & Unemployed & 94 & 42 & $2.72(1.23-6.02)$ & I.79 (0.7I-4.56) \\
\hline \multirow[t]{4}{*}{ Worst events } & Physical assault & 138 & 102 & I.IO (0.5I-2.39) & $\mathrm{I} .34(0.53-3.4 \mathrm{I})$ \\
\hline & Being in a war fighting situation & 146 & 72 & $1.65(0.75-3.6 I)$ & $2.01(0.78-5.17)$ \\
\hline & Destruction of personal property & 65 & 58 & $0.91(0.40-2.05)$ & $1.11(0.42-2.91)$ \\
\hline & $\begin{array}{l}\text { Did not access medical care during the } \\
\text { event }\end{array}$ & 16 & 13 & 1 & I \\
\hline \multirow{2}{*}{$\begin{array}{l}\text { A family member or friend was injured } \\
\text { or killed }\end{array}$} & Yes & 58 & 28 & $1.46(0.90-2.37)$ & $1.95(1.10-3.48)^{*}$ \\
\hline & No & 307 & 217 & 1 & I \\
\hline \multirow[t]{2}{*}{ Family mental illness } & Yes & 18 & 20 & $0.58(0.30-1.13)$ & $0.69(0.32-1.5 I)$ \\
\hline & No & 347 & 225 & I & I \\
\hline
\end{tabular}

(Continued) 
Table 2 (Continued).

\begin{tabular}{|c|c|c|c|c|c|}
\hline & & \multicolumn{2}{|c|}{ PTSD } & \multirow[b]{2}{*}{ COR } & \multirow[b]{2}{*}{ AOR $(95 \% \mathrm{Cl})$} \\
\hline & & Yes & No & & \\
\hline \multirow[t]{2}{*}{ Having chronic medical illness } & Yes & 81 & 72 & $0.69(0.47-0.99)$ & $0.89(0.56-1.40)$ \\
\hline & No & 284 & 173 & 1 & I \\
\hline \multirow[t]{2}{*}{ Current use of khat } & Yes & 71 & 56 & $0.82(0.55-1.21)$ & $1.08(0.64-1.83)$ \\
\hline & No & 294 & 189 & 1 & I \\
\hline \multirow[t]{2}{*}{ Current use of alcohol } & Yes & 146 & 128 & $0.61(0.44-0.85)$ & $0.70(0.46-1.06)$ \\
\hline & No & 219 & 117 & 1 & I \\
\hline \multirow[t]{2}{*}{ Current cigarette smoking } & Yes & 55 & 54 & $0.63(0.41-0.95)$ & $1.07(0.6 \mathrm{I}-1.9 \mathrm{I})$ \\
\hline & No & 310 & 191 & 1 & I \\
\hline \multirow[t]{2}{*}{ Depression } & Yes & 216 & 106 & $1.90(1.37-2.64)$ & $1.67(1.13-2.47)^{*}$ \\
\hline & No & 149 & 139 & 1 & I \\
\hline \multirow[t]{3}{*}{ Social support } & Poor social support & 221 & 161 & $0.67(0.40-1.12)$ & $1.13(0.60-2.11)$ \\
\hline & Moderate social support & 91 & 58 & $0.77(0.43-1.37)$ & $1.10(0.56-2.16)$ \\
\hline & Strong social support & 53 & 26 & 1 & I \\
\hline \multirow[t]{3}{*}{ Perceived life threat } & Low perceived threat & 36 & 80 & 1 & I \\
\hline & Moderate perceived threat & 202 & 119 & $3.77(2.40-5.94)$ & $3.35(1.98-5.68)^{* * *}$ \\
\hline & High perceived threat & 127 & 46 & $6.14(3.65-10.30)$ & $3.66(1.93,6.96)^{* * *}$ \\
\hline \multirow[t]{2}{*}{ Anxiety } & Yes & 208 & 88 & $2.36(1.69-3.30)$ & $1.85(1.21-2.83)^{* *}$ \\
\hline & No & 157 & 157 & 1 & I \\
\hline \multirow[t]{3}{*}{ Level of exposure } & Direct & 124 & 27 & $4.59(1.74-12.12)$ & $3.27(1.09-9.83)^{*}$ \\
\hline & Witnessed it & 231 & 208 & I.II (0.45-2.72) & $0.85(0.29-2.25)$ \\
\hline & Job related & 10 & 10 & 1 & I \\
\hline
\end{tabular}

Notes: $* P<0.05$ (variables significantly associated with PTSD), ${ }^{*} p \leq 0.01$ and ${ }^{* * *} p \leq 0.001$; chi-square $=6.9 ; \mathrm{df}=8$; Hosmer-Lemeshow test $=0.55$.

\section{Discussion}

Post-traumatic stress disorder is becoming a serious public health problem in low- and middle-income countries following exposure to man-made catastrophes such as ethnic-based conflicts, terrorist acts, and civil wars. Ethiopia is one of the conflict prone countries as a result of its ethnic based administrative structure. The November 2020 massacre of Maikadra town is one of the most serious events in the country that resulted in the death of more than 1,650 civilians of the Amhara ethnic group. Our study showed that six in 10 residents had post-traumatic stress disorder 6 months after the incident. Hence the prevalence of post-traumatic stress disorder was 59.8\% (95\% CI=55.7-63.9). This result is consistent with other findings of other African countries that reported a prevalence rate of PTSD of $60 \%$ in Nigeria $^{33}$ and $63 \%$ prevalence rate of PTSD in among internally displaced victims of boko haram terrorism in NorthEastern Nigeria ${ }^{51}$ and $58.4 \%$ among internally displaced individuals in Ethiopia. ${ }^{12}$ However, the prevalence of PTSD in the current study was lower than other previous studies, $82 \%$ in Kenya, ${ }^{36} 65.7 \%$ in Nigeria, ${ }^{34} 74 \%$ in Uganda, ${ }^{29}$ and $76.5 \%{ }^{23}$ and $68.9 \%{ }^{24}$ in Palestine. The difference could be explained by the population composition participating. For example, the Palestinian study was limited to adolescents who were in refugee camps during the Al-Aqsa intifada who 
were badly injured due to continuing conflict where the traumatic experience was severe and lasted for extended periods of time that increased their vulnerability. Hence, several studies have confirmed that as the level of exposure to traumatic events, such as the number or intensity of the experienced events increases, so does the rate of PTSD. ${ }^{52}$ Conversely, the prevalence of PTSD in the current study was higher than the studies conducted in other parts of Ethiopia, 37.3\% in Koshe landslide survivors (Addis Ababa), ${ }^{38} 15.4 \%{ }^{53}$ after a road traffic accident in South West Ethiopia, and other African countries, $24.8 \%$ in Rwanda, ${ }^{25} 46 \%$ in Nigeria, ${ }^{32} 48.3 \%$ in Liberia, ${ }^{30}$ as well as $29.3 \%$ in Southern Lebanon. ${ }^{54}$

In this study the odds of having PTSD were twice as high in women compared to men. ${ }^{12,39,56}$ Females are more likely than males to experience PTSD as a result of a lower threshold for psycho-trauma exposure. ${ }^{57}$ Women are more likely emotionally cope with stressful situations compared to men who employ problem-focused coping strategies. ${ }^{58}$ Women have been reported to be more sensitive and responsive to threats.

The odds of PTSD were twice as high among respondents whose close friends and/or family members were murdered or seriously injured during the massacre. This is supported by previous studies of a Rwanda genocide and in a Peru earthquake. The odds of developing PTSD among individuals who had moderate and severe perceived threat to life were 3.3- and 3.7-times higher, which is consistent with another Ethiopian study. ${ }^{12}$ Direct exposure to the traumatic event increased the odds of having PTSD. This is supported by studies conducted in an Ethiopian Koshe landslide (Addis Ababa) $)^{38}$ and Palestine's Gaza.

Symptoms of depression and anxiety were also found to be independent predictors of PTSD. ${ }^{12}$ This is similar to findings done on incarcerated veterans in the King County Jail system in Seattle and King County, Washington, and in Kenya. $^{36}$

\section{Limitations}

We were not able to verify whether the depressive and anxiety symptoms as well as substance use preceded or followed the PTSD due to the cross-sectional nature of the study.

\section{Conclusion}

This study was conducted in an area where a serious massacre to an Amhara ethnic group was committed which left many terrified. Six out of ten of the residents suffered from PTSD following the killings of more than 1,560 innocent civilians where more than one-third of the respondents lost family members. Women, those who lost family members, individuals with high perceived threat to life and those with symptoms of mental illnesses were the most affected. This implies that the intense and persistent emotional disturbances need urgent psychosocial interventions.

\section{Abbreviations}

AOR, Adjusted Odds Ratio; CI, Confidence Interval; CIDI, Composite International Diagnostic Interview; COR, Crude Odds Ratio; GAD, Generalized Anxiety Disorder; PCL-C, Posttraumatic stress disorder Checklist Civilian version; PCL5, Posttraumatic stress disorder, fifth edition; PHQ-9, Patient Health Questionnaire 9 items; PSS, Perceived Stress Scale; PTSD, Post Traumatic Stress Disorder.

\section{Ethics Approval and Informed Consent}

All procedures undertaken during data collection were in accordance with the ethical review board of the University of Gondar and the declaration of Helsinki. Ethical approval was obtained from the Ethical review committee of the college of medicine and health sciences, University of Gondar. A formal letter of permission was obtained from the department of Psychiatry. The participants were informed about the aim of the study and no name was recorded, instead codes were used to maintain confidentiality. They were given the information sheet to read and for those who were unable to read, the data collectors read for them and asked them if they understood. The study participants were also informed of their right to refuse, withdraw, or refrain from answering questions they are not comfortable with and this would not have any reprisal. They were assured that their decision wouldn't affect their future medical service. Finally, data were collected after obtaining written consent. Participants with serious suicidal ideation during the interview were advised to visit the nearby health center. 


\section{Acknowledgments}

The authors would like to thank the University of Gondar for funding the research. We are very grateful to the zonal administration of Setit Humera for granting us permission to conduct this research among Maikadra residents. We also extend our acknowledgments to the research participants, data collectors, and supervisors for their time and effort.

\section{Author Contributions}

All authors conceptualized the research problem, drafted the proposal, developed the data collection tools, supervised the data collection process, contributed to data analysis, revised the manuscript, have agreed on the journal to which the article was submitted, gave final approval of the version to be published, and agree to be accountable for all aspects of the work.

\section{Disclosure}

All authors declared that they have no conflicts of interest for this work.

\section{References}

1. Hall BJ, Olff M. Global Mental Health: Trauma and Adversity Among Populations in Transition. Taylor \& Francis; 2016.

2. Ng LC, Stevenson A, Kalapurakkel SS, et al. National and regional prevalence of posttraumatic stress disorder in sub-Saharan Africa: a systematic review and meta-analysis. PLoS Med. 2020;17(5):e1003090.

3. Charlson FJ, Steel Z, Degenhardt L, et al. Predicting the impact of the 2011 conflict in Libya on population mental health: PTSD and depression prevalence and mental health service requirements. PLoS One. 2012;7(7):e40593. doi:10.1371/journal.pone.0040593

4. Paracchini D, Phil S, Steer CD, et al. Association of the KIAA0319 dyslexia susceptibility gene with reading skills in the general population. Am J Psychiatr. 2008;165(12):1576-1584. doi:10.1176/appi.ajp.2008.07121872

5. America Psychiatric Association. Diagnostic and Statistical Manual of Mental Disorders. America Psychiatric Association; $2013: 21$.

6. Hoppen TH, Morina N. The prevalence of PTSD and major depression in the global population of adult war survivors: a meta-analytically informed estimate in absolute numbers. Eur J Psychotraumatol. 2019;10(1):1578637. doi:10.1080/20008198.2019.1578637

7. Koenen K, Ratanatharathorn A, Ng L, et al. Posttraumatic stress disorder in the world mental health surveys. Psychol Med. 2017;47 (13):2260-2274. doi:10.1017/S0033291717000708

8. Sadock B, Sadock V. Kaplan and Saddock's comprehensive textbook of psychiatry. In: Aydın H, Bozkurt A, editors. Sekizinci Baskı Güneş Kitabevleri Istanbul. Lippincot Williams \& Wilkins; 2007:1559-1800.

9. Ataman M. Prevalence of PTSD and related factors in communities living in conflictual area: Diyarbakir case. 2008.

10. Bass JK, Annan J, McIvor Murray S, et al. Controlled trial of psychotherapy for Congolese survivors of sexual violence. N Engl J Med. 2013;368 (23):2182-2191. doi:10.1056/NEJMoa1211853

11. De Jong JT, Komproe IH, Van Ommeren M, et al. Lifetime events and posttraumatic stress disorder in 4 postconflict settings. JAMA. 2001;286 (5):555-562. doi:10.1001/jama.286.5.555

12. Madoro D, Kerebih H, Habtamu Y. Post-traumatic stress disorder and associated factors among internally displaced people in South Ethiopia: a cross-sectional study. Neuropsychiatr Dis Treat. 2020;16:2317. doi:10.2147/NDT.S267307

13. Kalipeni E, Oppong J. The refugee crisis in Africa and implications for health and disease: a political ecology approach. Soc Sci Med. $1998 ; 46$ (12):1637-1653. doi:10.1016/S0277-9536(97)10129-0

14. Kessler RC, Sonnega A, Bromet E, Hughes M, Nelson CB. Posttraumatic stress disorder in the National Comorbidity Survey. Arch Gen Psychiatry. 1995;52(12):1048-1060. doi:10.1001/archpsyc.1995.03950240066012

15. Ferry F, Bunting B, Murphy S, O’Neill S, Stein D, Koenen K. Traumatic events and their relative PTSD burden in Northern Ireland: a consideration of the impact of the 'Troubles'. Soc Psychiatry Psychiatr Epidemiol. 2014;49(3):435-446. doi:10.1007/s00127-013-0757-0

16. Tanielian TL, Tanielian T, Jaycox L. Invisible Wounds of War: Psychological and Cognitive Injuries, Their Consequences, and Services to Assist Recovery. Rand Corporation; 2008.

17. Onyut LP, Neuner F, Ertl V, Schauer E, Odenwald M, Elbert T. Trauma, poverty and mental health among Somali and Rwandese refugees living in an African refugee settlement-an epidemiological study. Confl Health. 2009;3(1):1-16. doi:10.1186/1752-1505-3-6

18. Bedaso A, Kediro G, Ebrahim J, et al. Prevalence and determinants of post-traumatic stress disorder among road traffic accident survivors: a prospective survey at selected hospitals in southern Ethiopia. BMC Emerg Med. 2020;20(1):1-10. doi:10.1186/s12873-020-00348-5

19. Luitel NP, Jordans MJ, Sapkota RP, et al. Conflict and mental health: a cross-sectional epidemiological study in Nepal. Soc Psychiatry Psychiatr Epidemiol. 2013;48(2):183-193. doi:10.1007/s00127-012-0539-0

20. Sepahvand H, Mokhtari Hashtjini M, Salesi M, Sahraei H, Pirzad Jahromi G. Prevalence of post-traumatic stress disorder (PTSD) in Iranian population following disasters and wars: a systematic review and meta-analysis. Iran J Psychiatr Behav Sci. 2019;13(1):12.

21. Canetti D, Galea S, Hall BJ, Johnson RJ, Palmieri PA, Hobfoll SE. Exposure to prolonged socio-political conflict and the risk of PTSD and depression among Palestinians. Psychiatry. 2010;73(3):219-231. doi:10.1521/psyc.2010.73.3.219

22. Khamis V. Post-traumatic stress and psychiatric disorders in Palestinian adolescents following intifada-related injuries. Soc Sci Med. 2008;67 (8):1199-1207. doi:10.1016/j.socscimed.2008.06.013

23. Elbedour S, Onwuegbuzie AJ, Ghannam J, Whitcome JA, Hein FA. Post-traumatic stress disorder, depression, and anxiety among Gaza Strip adolescents in the wake of the second Uprising (Intifada). Child Abuse Negl. 2007;31(7):719-729. doi:10.1016/j.chiabu.2005.09.006

24. Pham PN, Weinstein HM, Longman T. Trauma and PTSD symptoms in Rwanda: implications for attitudes toward justice and reconciliation. JAMA. 2004;292(5):602-612. doi:10.1001/jama.292.5.602 
25. Fodor KE, Pozen J, Ntaganira J, Sezibera V, Neugebauer R. The factor structure of posttraumatic stress disorder symptoms among Rwandans exposed to the 1994 genocide: a confirmatory factor analytic study using the PCL-C. J Anxiety Disord. 2015;32:8-16. doi:10.1016/j. janxdis.2015.03.001

26. Watts S, Mackenzie A, Thomas C, et al. CBT for depression: a pilot RCT comparing mobile phone vs. computer. BMC Psychiatr. 2013;13(1):1-9. doi:10.1186/1471-244X-13-49

27. Weierstall R, Schalinski I, Crombach A, Hecker T, Elbert T. When combat prevents PTSD symptoms-results from a survey with former child soldiers in Northern Uganda. BMC Psychiatr. 2012;12(1):1-8.

28. Galea S, Rockers PC, Saydee G, Macauley R, Varpilah ST, Kruk ME. Persistent psychopathology in the wake of civil war: long-term posttraumatic stress disorder in Nimba County, Liberia. Am J Public Health. 2010;100(9):1745-1751. doi:10.2105/AJPH.2009.179697

29. Tagurum YO, Chirdan OO, Obindo T, et al. Prevalence of violence and symptoms of post-traumatic stress disorder among victims of ethnoreligious conflict in Jos, Nigeria. 2014.

30. Beiser M, Wiwa O, Adebajo S. Human-initiated disaster, social disorganization and post-traumatic stress disorder above Nigeria's oil basins. Soc Sci Med. 2010;71(2):221-227. doi:10.1016/j.socscimed.2010.03.039

31. Abiama EE, Ifeagwazi CM, Chukwuorji JC. Rates of occurrence and influence of trauma exposure on posttraumatic stress disorder symptoms among survivors of terrorist attacks in Northeast Nigeria. Int J Ment Health Addict. 2021;1-15. doi:10.1007/s11469-021-00527-w

32. Jenkins R, Othieno C, Omollo R, et al. Probable post traumatic stress disorder in Kenya and its associated risk factors: a cross-sectional household survey. Int J Environ Res Public Health. 2015;12(10):13494-13509. doi:10.3390/ijerph121013494

33. Njau JW. Posttraumatic Stress Disorder Among the Heads of Households of Ethnic Clashes Survivors in the Rift Valley Province, Kenya: A Comparative Study. University of Nairobi; 2005.

34. Ayazi T, Lien L, Eide AH, Ruom MM, Hauff E. What are the risk factors for the comorbidity of posttraumatic stress disorder and depression in a war-affected population? A cross-sectional community study in South Sudan. BMC Psychiatr. 2012;12(1):1-12. doi:10.1186/1471-244X-12-175

35. Asnakew S, Shumet S, Ginbare W, Legas G, Haile K. Prevalence of post-traumatic stress disorder and associated factors among Koshe landslide survivors, Addis Ababa, Ethiopia: a community-based, cross-sectional study. BMJ Open. 2019;9(6):e028550. doi:10.1136/bmjopen-2018-028550

36. Fares J, Gebeily S, Saad M, et al. Post-traumatic stress disorder in adult victims of cluster munitions in Lebanon: a 10 -year longitudinal study. BMJ Open. 2017;7(8):e017214. doi:10.1136/bmjopen-2017-017214

37. Farhood LF, Fares S, Sabbagh R, Hamady C. PTSD and depression construct: prevalence and predictors of co-occurrence in a South Lebanese civilian sample. Eur J Psychotraumatol. 2016;7(1):31509. doi:10.3402/ejpt.v7.31509

38. Eytan A, Gex-Fabry M, Toscani L, Deroo L, Loutan L, Bovier PA. Determinants of postconflict symptoms in Albanian Kosovars. J Nerv Ment Dis. 2004;192(10):664-671. doi:10.1097/01.nmd.0000142029.96703.57

39. Cohen MH, d'Adesky A-C, Anastos K. Women in Rwanda: another world is possible. JAMA. 2005;294(5):613-615. doi:10.1001/jama.294.5.613

40. Shalev A, Liberzon I, Marmar C, Longo DL. Post-traumatic stress disorder. N Engl J Med. 2017;376(25):2459-2469. doi:10.1056/NEJMra1612499

41. Nazarian D, Kimerling R, Frayne SM. Posttraumatic stress disorder, substance use disorders, and medical comorbidity among returning US veterans. J Trauma Stress. 2012;25(2):220-225.

42. Weathers FW, Litz BT, Keane TM, Palmieri PA, Marx BP, Schnurr PP. The ptsd checklist for dsm-5 (pcl-5). Scale available from the National Center for PTSD at www ptsd va gov. 2013:10.

43. Abiola T, Udofia O, Zakari M. Psychometric properties of the 3-item Oslo social support scale among clinical students of Bayero University Kano, Nigeria. Malay J Psychiatr. 2013;22(2):32-41.

44. Cohen S, Kamarck T, Mermelstein R. Perceived stress scale. Measur Stress. 1994;10:1-2.

45. Manea L, Gilbody S, McMillan D. Optimal cut-off score for diagnosing depression with the Patient Health Questionnaire (PHQ-9): a meta-analysis. Cmaj. 2012;184(3):E191-E196. doi:10.1503/cmaj.110829

46. Taru MY, Bamidele LI, Makput DM, et al. Posttraumatic stress disorder among internally displaced victims of Boko Haram terrorism in north-eastern Nigeria. Jos J Med. 2018;12(1):8-15.

47. Frans Ö, Rimmö PA, Åberg L, Fredrikson M. Trauma exposure and post-traumatic stress disorder in the general population. Acta Psychiatr Scand. 2005;111(4):291. doi:10.1111/j.1600-0447.2004.00463.x

48. Yohannes K, Gebeyehu A, Adera T, Ayano G, Fekadu W. Prevalence and correlates of post-traumatic stress disorder among survivors of road traffic accidents in Ethiopia. Int J Ment Health Syst. 2018;12(1):1-8. doi:10.1186/s13033-018-0229-8

49. Farhood L, Dimassi H, Lehtinen T. Exposure to war-related traumatic events, prevalence of PTSD, and general psychiatric morbidity in a civilian population from Southern Lebanon. J Transcult Nurs. 2006;17(4):333-340. doi:10.1177/1043659606291549

50. Ben-Zion Z, Fine NB, Keynan NJ, et al. Cognitive flexibility predicts PTSD symptoms: observational and interventional studies. Front Psychiatr. 2018;9:477. doi:10.3389/fpsyt.2018.00477

51. Richards A, Ospina-Duque J, Barrera-Valencia M, et al. Posttraumatic stress disorder, anxiety and depression symptoms, and psychosocial treatment needs in Colombians internally displaced by armed conflict: a mixed-method evaluation. Psychol Trauma. 2011;3(4):384. doi:10.1037/ a0022257

52. Tamres LK, Janicki D, Helgeson VS. Sex differences in coping behavior: a meta-analytic review and an examination of relative coping. Personal Soc Psychol Rev. 2002;6(1):2-30. doi:10.1207/S15327957PSPR0601_1

53. Galen BR, Underwood MK. A developmental investigation of social aggression among children. Dev Psychol. 1997;33(4):589. doi:10.1037/00121649.33.4.589

54. Munyandamutsa N, Nkubamugisha PM, Gex-Fabry M, Eytan A. Mental and physical health in Rwanda 14 years after the genocide. Soc Psychiatry Psychiatr Epidemiol. 2012;47(11):1753-1761.

55. Cairo JB, Dutta S, Nawaz H, Hashmi S, Kasl S, Bellido E. The prevalence of posttraumatic stress disorder among adult earthquake survivors in Peru. Disaster Med Public Health Prep. 2010;4(1):39-46. doi:10.1017/S1935789300002408

56. Afana AH, Dalgard OS, Bjertness E, Grunfeld B, Hauff E. The prevalence and associated socio-demographic variables of post-traumatic stress disorder among patients attending primary health care centres in the Gaza Strip. J Refug Stud. 2002;15(3):283-295. doi:10.1093/jrs/15.3.283

57. Alenko A, Berhanu H, Tareke AA, et al. Posttraumatic stress disorder and associated factors among drivers surviving road traffic crashes in Southwest Ethiopia. Neuropsychiatr Dis Treat. 2019;15:3501. doi:10.2147/NDT.S233976 
58. Saxon AJ, Davis TM, Sloan KL, McKnight KM, McFall ME, Kivlahan DR. Trauma, symptoms of posttraumatic stress disorder, and associated problems among incarcerated veterans. Psychiatr Services. 2001;52(7):959-964. doi:10.1176/appi.ps.52.7.959

\section{Publish your work in this journal}

Psychology Research and Behavior Management is an international, peer-reviewed, open access journal focusing on the science of psychology and its application in behavior management to develop improved outcomes in the clinical, educational, sports and business arenas. Specific topics covered in the journal include: Neuroscience, memory and decision making; Behavior modification and management; Clinical applications; Business and sports performance management; Social and developmental studies; Animal studies. The manuscript management system is completely online and includes a very quick and fair peer-review system, which is all easy to use. Visit http://www.dovepress.com/testimonials.php to read real quotes from published authors.

Submit your manuscript here: https://www.dovepress.com/psychology-research-and-behavior-management-journal 